\title{
On linear independence of trigonometric numbers
}

\section{ARNO BERGER}

\author{
ABSTRACT. \\ A necessary and sufficient condition is established for $1, \cos \left(\pi r_{1}\right)$, and $\cos \left(\pi r_{2}\right)$ to be rationally independent, \\ where $r_{1}, r_{2}$ are rational numbers. The elementary computational argument yields linear independence over \\ larger number fields as well.
}

Acknowledgements. The author was supported by an NSERC Discovery Grant. He is much indebted to S. Gille and A. Weiss for helpful discussions and comments. He also wishes to thank J. Calcut and G. Molteni for bringing several important references to his attention, and an anonymous referee for suggestions that helped improve the exposition of this note.

\section{REFERENCES}

[1] Bachman, G., On the coefficients of cyclotomic polynomials, Mem. Amer. Math. Soc., No. 510, (1993)

[2] Calcut, J. S., Rationality and the Tangent Function, preprint available at http://www.oberlin.edu/faculty/jcalcut/papers.htm, accessed 26 April 2017

[3] Conway, J. H. and Jones, A. J., Trigonometric Diophantine equations (On vanishing sums of roots of unity), Acta Arith., 30 (1976), 229-240

[4] Fröhlich, A. and Taylor, M. J., Algebraic number theory, Cambridge University Press, 1991

[5] Hardy, G. H. and Wright, E. M., An Introduction to the Theory of Numbers, fourth ed., Clarendon Press, Oxford, 1960

[6] Hungerford, T. W., Algebra, Graduate Texts in Mathematics, No. 73, Springer, 1974

[7] Jahnel, J., When is the (co)sine of a rational angle equal to a rational number?, preprint arXiv 1006.2938, 2010

[8] Janusz, G. J., Algebraic Number Fields, Academic Press, 1973

[9] Kunz, E., Algebra, Vieweg, 1991

[10] Lam, T. Y. and Leung, K. H., On vanishing sums of roots of unity, J. Algebra, 224 (2000), 91-109

[11] Lehmer, D. H., A note on trigonometric algebraic numbers, Amer. Math. Monthly, 40 (1933), 165-166

[12] Mann, H. B., On linear relations between roots of unity, Mathematika, 12 (1965), 107-117

[13] Niven, I., Irrational numbers, Carus Monographs, No. 11, The Mathematical Association of America, 1956

[14] Stroth, G., Algebra, de Gruyter, 1998

[15] Underwood, R. S., On the irrationality of certain trigonometric functions, Amer. Math. Monthly, 28 (1921), 374-376

[16] Varona, J. L., Rational values of the arccosine function, Cent. Eur. J. Math., 4 (2006), 319-322

UNIVERSITY OF ALBERTA

MATHEMATICAL AND STATISTICAL SCIENCES

EDMONTON, ALBERTA, CANADA

E-mail address: berger@ualberta.ca

Received: 28.04.2017; In revised form: 01.03.2018; Accepted: 08.03.2018

2010 Mathematics Subject Classification. 11R09, 11R11, 12Y05.

Key words and phrases. Niven's Theorem, trigonometric number, rational (in)dependence, cyclotomic polynomial, real quadratic number field. 